\title{
The GAIRS Checklist: a useful global assessment tool in patients with Rett syndrome
}

\author{
Rosa Angela Fabio ${ }^{1 *} \mathbb{0}$, Martina Semino² and Samantha Giannatiempo ${ }^{3}$
}

\begin{abstract}
Background: Rett Syndrome is a severe, neurodevelopmental disorder mainly caused by mutations in the MECP2 gene, affecting around 1 in 10,000 female births. Severe physical, language, and social impairments impose a wide range of limitations in the assessment of the abilities of Rett patients. This study proposes an analysis and first validation of a Global Assessment and Intervention in Rett syndrome (GAIRS) Checklist for assessing behavioral, intellectual, academic, neuropsychological and psychosocial manifestations in patients with Rett Syndrome. We administered the GAIRS Checklist to 113 Italian patients with Rett Syndrome aged 4-42.

Aims of this study: To examine the psychometric characteristics of the GAIRS Checklist. Moreover, the aim is also to examine the validity of GAIRS with test-retest correlation, convergent validity with similar functional measurements, such as the Vineland scales, and divergent validity with severity of disease scale, such as the RARS scale and severity of neuropsychiatric evaluations.

Results: All 10 subscales of GAIRS were positively and significantly related to each other and to the total GAIRS score, and the subscales showed high levels of Cronbach's alpha values (from .77 to .95). Principal axis factoring suggested two factors that explain $60 \%$ of the variance. Test-retest reliability is 0.82 . This means that psychometric properties are reliable. Correlation for Concurrent validity with Vineland score was high and Divergent Validity with RARS was also high.

Conclusion: The GAIRS Checklist used for Rett syndrome is acceptable and feasible to complete assessment in a clinical setting. Moreover, it can detect the complexity of this disease and may suggest the next step in terms of specific training in Rett syndrome.
\end{abstract}

Keywords: Rett syndrome (RTT), Assessment, Global function, GAIRS Checklist

\section{Background}

Rett syndrome (RTT) is a severe, neurodevelopmental disorder mainly caused by mutations in the MECP2 gene, affecting around 1 in 10,000 female births [1]. Clinical manifestations include severe linguistic and motor impairments that are the core of phenotype symptoms. A child affected by RTT initially appears to follow a typical development path, but at about 18 months of age a

*Correspondence: rafabio@unime.it

${ }^{1}$ Department of Clinical and Experimental Medicine, via Bivona, 98121 Messina, Italy

Full list of author information is available at the end of the article subtle regression in developmental acquisitions begins, opening the path to the clinical stages [2]. Loss of previously acquired language skills and of purposeful hand use, increasing difficulties in motor abilities (dyspraxia) and mental retardation are the clearest signs of regression involved in RTT. Other typical signs of RTT appear including hand stereotypies-such as handwashing, hand-wringing, hand-mouthing-breathing disorders (breath holding and hyperventilation), ataxia, agnosia, bruxism and epilepsy [3-6].

Several assessments on patients with RTT have been conducted on cognitive abilities, on communicational abilities and on motor abilities [7-11]; only few of these original author(s) and the source, provide a link to the Creative Commons licence, and indicate if changes were made. The images or other third party material in this article are included in the article's Creative Commons licence, unless indicated otherwise in a credit line to the material. If material is not included in the article's Creative Commons licence and your intended use is not permitted by statutory regulation or exceeds the permitted use, you will need to obtain permission directly from the copyright holder. To view a copy of this licence, visit http://creativecommons.org/licenses/by/4.0/. The Creative Commons Public Domain Dedication waiver (http://creativeco mmons.org/publicdomain/zero/1.0/) applies to the data made available in this article, unless otherwise stated in a credit line to the data. 
have carried out a global functional assessment of all the abilities of these patients. Assessment of the cognitive skills of patients with RTT, as well as other individuals with severe motor and communication limitations, is extremely challenging. [7] Neuropsychological and cognitive assessments are generally developed for and standardized with typically developing children who do not have physical impairments [12]. When standard assessment procedures requiring manual motor functioning for responding have been used to evaluate cognitive functioning, patients with RTT generally achieve age-equivalent performances close to young infants [13, 14]. Severe physical, language, and social impairments impose a wide range of limitations [2-5]. With reference to communication abilities, some studies $[15,16]$ have aimed to recognize any communicative acts (vocalizations, hand movement stereotypies, body movements, facial expressions, or eye gaze) that would represent a consistent and unequivocal response used by participants with RTT.

With reference to the assessment of motor abilities, available clinical scales do not comprehensively capture the variability of presentation of gait and postural abnormalities in Rett Syndrome patients. Griffiths scales [17] appear too specific to assess peculiar patterns of (loco-) motor derangements in RTT. In addition, the standardization sample included children aged 0-72 months and therefore, similar to the standardization sample of the Bayley scales [18], is not appropriate to test older children or adolescents. There is another motor scale specific for RTT and already validated: the Rett Syndrome Gross Motor Scale (RSGMS) [19]. Rodocanachi et al. [20], in a new standardized scale, the Rett Syndrome Motor Evaluation Scale (RESMES), added postural transitions and walking up or downstairs. RESMES items are centered on the International Classification of Functioning construct of patient's capacity, which reflects what an individual can do in a semi-standardized environment and have been conceived to capture fine-grained characteristics of movement. Regarding a general assessment, there are two scales that can be used to assess children with special needs: the Portage Guide to Early Education Checklist [21] and the Bayley Scales of Infant Development [18]. The Portage Guide to Early Education Checklist [21] was developed by the Portage Project home intervention program which has been serving preschool multiple children with special needs in Wisconsin, USA. The guide has two parts: a developmental checklist which lists sequential behaviors from birth through five years of age in five learning areas and a set of curriculum cards which match each of the 450 behaviors listed on the checklist. The check-list has been used to pinpoint behaviors and measure change. The cards have been used in establishing individual home training prescriptions [21]. The Bayley
Scales of Infant Development [18] consist of a mental scale of 103 items and a motor scale of 81 items. The scales have been designed to measure growth and development from birth to 30 months of age. The instrument was developed primarily for clinical and research use. According to Holden [18], the Bayley Scales have been invaluable in filling a longstanding need for a well standardized, reliable instrument to assess the developmental progress of infants.

With reference to the global assessment of the abilities in Rett syndrome, there are few instruments that can measures the global functional abilities of RTT patients. Some assessments have been carried out by interviewing the parents or caregivers using the Vineland Adaptive Behavior Scales-Interview second edition (VABS), and the Rett Assessment Rating Scales (RARS) [22]. VABS [23] is subdivided into four domains: communication; daily living; socialization; and motor skills. The interviewer asks general questions pertaining to the patient's functioning in each domain and uses the responses to rate the examinee on each critical behavior item (2: always present, 1 : sometimes present, 0 : seldom or never present). Typical interviews require approximately one hour. A total score is computed by summing the individual ratings for each scale. Another general assessment scale has been created to evaluate level of severity in RTT patients-RARS [22]. This scale is organized into seven domains: cognitive, sensorial, motor, emotional, autonomy, typical characteristics of the disease and of behavior. A total of 31 items was generated as representative of the profile of RTT. Each item is provided with a brief glossary explaining its meaning in a few words. Each item is rated on a 4-point scale, where $1=$ within normal limits, $2=$ infrequent or low abnormality, $3=$ frequent or medium-high abnormality, and $4=$ strong abnormality. Intermediate ratings are possible; for example, an answer between 2 and 3 points is rated as 2.5. For each item, the evaluator circles the number corresponding to the best description of the patient. After a patient has been rated on all 31 items, a total score is computed by summing the individual ratings. This total score allows the evaluator to identify the level of severity of RTT, conceptualized as a continuum ranging from mild symptoms to severe deficits $($ Mild $=0-55$; Moderate $=56-81$; Severe $=>81$ ).

Summarizing, the main limitations of the scales presented here are firstly, in some scales like VABS and RARS parents and caregivers are requested to evaluate patients' abilities through simple observation and not through direct evaluation by therapists; secondly, in some of these scales not all the areas of manifestations in RTT are considered (behavioral, intellectual, academic, neuropsychological and psychosocial); finally not all of these scales are presented hierarchically and they may not be 
valid for the assessment or for suggesting all the next level of the steps necessary for any eventual intervention.

In the present work, we proposed the Global Assessment and Intervention in Rett syndrome (GAIRS) to overcome all these limitations. The aim of this study is to examine the preliminary psychometric characteristics of the GAIRS Checklist. Furthermore, the aim is to examine the validity of GAIRS with test-retest correlation, convergent validity with similar functional measurements such as the Vineland scales, divergent validity with severity of disease scale such as the RARS scale and neuropsychiatric evaluations. A specific GAIRS Checklist has been developed to assess behavioral, intellectual, academic, neuropsychological and psychosocial manifestations in patients with Rett Syndrome. The purpose of the Checklist is to offer an easy-to-use, short and accessible tool for every health-care professional to assess all the abilities but also to identify patients needing next-step evaluation and treatment. Thanks to the hierarchical order of all the targets assessed in each area of GAIRS, this Checklist can be a useful instrument not only for assessment but also for any eventual intervention.

\section{Methods}

\section{Patient characteristics}

GAIRS was administered to 113 consecutively enrolled Rett patients ( 111 females, mean age $18.39 \pm 10.19$ years), from the Italian Rett Association. All 113 patients, aged from 4 to 45 years, met the diagnostic clinical criteria for Rett Syndrome and underwent specific genetic tests.

RTT patients were classified as clinical stage III (characterized by prominent hand apraxia/dyspraxia, apparently preserved ambulation ability, and some communicative ability, mainly eye contact) or stage IV (late motor deterioration, with progressive loss of ambulation ability), according to the criteria for classic RTT by Hagberg et al. [4]. Their demographic, developmental, clinical, behavioral, and genetic information, collected from all available sources (parent/caregiver reports of history and current behavior and features, previous clinical reports, and direct observation and examination of the patients) was entered into a database.

The Mecp 2 mutation was seen in $80 \%$ of the sample; specific mutations of the Mecp 2 gene were: $5 \%$ showed C7D3C, 10\% showed R294X, 10\% showed C965C, 10\% showed R255X, 15\% showed P152R and 30\% showed T158M. Instead, for $20 \%$, it was not possible to specify the type of gene mutation, but all the typical phenotypic characteristics of RTT were observed. We asked the reference neuropsychiatry of each patient to give a medical judgment of severity based on typical characteristics of the syndrome (epilepsy, mood swings, convulsions, aerophagia, scoliosis). The severity level ranges from 5 (mild severity) to 20 (severe severity).
Table 1 Clinical characteristics

\begin{tabular}{ll}
\hline & Rett patients $(\mathbf{n}=\mathbf{1 1 3})$ \\
\hline Man age (years) \pm SD & $18.39 \pm 10.19$ \\
Range & $4-45$ \\
Gender f/m & $111 / 2$ \\
Diagnostic criteria met for Rett & 113 \\
Genetic mutations & Mecp2 \\
$\begin{array}{ll}\text { Mean severity index in relation to typical char- } \\
\text { acteristics of syndrome }\end{array}$ & $9(\min 5-\max 20)$ \\
\hline
\end{tabular}

Mean severity index in relation to the typical characteristics of the syndrome is 9 . Table 1 shows the clinical characteristics of the participants.

\section{Materials}

GAIRS is a global assessment and intervention rating scales checklist for Rett syndrome with items coming from the items of assessment in multi-disability disorders adapted to Rett syndrome [24-28]. Through a global analysis, it gives an overview of the different areas and is intended for use in a functional analysis of the overall abilities of the patient.

The GAIRS Checklist is composed of 10 macro-areas: basic or pre-requisite behavior, neuropsychological abilities, basic cognitive concepts, advanced cognitive concepts, communication abilities, emotional- affective abilities, hand motor skills, graphomotor skills, global motor abilities and level of autonomy in daily life. The 10 areas are described in Table 2. For each area, different sequential skills, hierarchically structured, are evaluated. Eighty-five skills in total are evaluated. Each skill has a numerical score ranging from 1 to 5 , where 1 is the minimum level of capacity and 5 is the maximum level of capacity to perform a specific activity. Below, we present some examples. In the area of basic behavior, the first skill that is evaluated is spontaneous eye contact. The score of this skill is: 1 If the child is unable to establish spontaneous eye contact, 2 if the child can establish spontaneous eye contact $2 / 3$ times out of 10 , 3 if the child can establish spontaneous eye contact $4 / 6$ times out of 10, 4 if the child can establish spontaneous eye contact $7 / 8$ times out of 10,5 if the child always establishes spontaneous eye contact. Instead, the sixth skill investigated in the hand motor area is grasping ability and its score is: 1 if the child cannot grasp an object on the table, 2 if the child can grasp a $5 \mathrm{~cm}$ object with palmar cubitus grip, 3 if the child can grasp a $5 \mathrm{~cm}$ object with palmar grip, 4 if the child can grasp a $1 \mathrm{~cm}$ object with pluri-digital grip, 5 if the child can grasp a $1 \mathrm{~cm}$ object with plier's grip (thumb-index). 
Table 2 Description of GAIRS checklist areas

1. Basic behaviors area

Evaluates the prerequisite behaviors for learning and communication, they are: spontaneous eye contact, eye contact on request, looking at objects, tracking objects and faces, functional gestures, cooperation with simple spoken requests (reply to their name, look for mother), sitting long enough to complete a task, object permanence, be able to wait for their turn before starting an activity, be able to communicate basic needs (need to eat, drink, sleep, play, walk, go to the bathroom, and feel good or bad)

2. Neuropsychological area

Evaluates brain-based skills which are needed in acquisition of knowledge, manipulation of information, and reasoning. They have more to do with the mechanisms of how people learn, remember, problem-solve, and pay attention, rather than with actual knowledge. This area includes selective attention, types and intensity of stereotypes, lateralization, temporal orientation, spatial orientation, memory span, logical sequences, categorization (animals, dress, foods, drinks, objects, places, actions)

3. Basic cognitive area

Evaluates the basic cognitive concepts that allow the understanding of reality (spatial concepts, topological concepts, etc.). This area includes object recognition, color discrimination, geometric form discrimination measure concepts, spatial concepts, human body discriminations, time concepts, cause-effect relationship

4. Advanced cognitive area

Evaluates the concepts of school learning that include the sub-areas of writing and mathematics. This area includes global words recognition, syllables recognition, recompleting words through syllables, alphabetic symbols recognition, recompleting words with alphabetic symbols, recognition of words representing actions, using words to communicate, math pre-requisite concepts, recognition of numbers, biunivocal relation between number and quantity

5. Communication area

Evaluates the development of language by measuring responses to environmental sounds and speech, as well as the production of sounds and words. The skills of communication, comprehension and expression that allow the person to interact with others. This area includes expressing a basic need at a corporal level, recognizing, and expressing a basic need through pictures, recognizing and expressing a basic need through word, understanding the biunivocal relation of a basic need between a picture and the word that expresses it, verbal comprehension, verbal production

6. Emotional area

Evaluates the person's abilities and ways of experiencing, expressing, and understanding their own emotions and those of others are analyzed. This area includes identify emotions and express emotions

7. Hand motor area

Evaluates the ability to make movements using the small muscles in our hands and wrists. Kids rely on these skills to do key tasks in school and in everyday life. Fine motor skills are complex, however. They involve the coordinated efforts of the brain and muscles, and they are built on the gross motor skills that allow us to make bigger movements. This area includes musculoskeletal alterations, hand-eye coordination during motor tasks lateralization, reaching movement, touching ability, grasping ability, releasing movement, repositioning movement, bimanual coordination, ability to push and pull an object

8. Graphomotor area

Evaluates the fine motor skills incorporating, among others, graphomotor skills (GS) which, in turn, involve strength and control of the finger muscles, and incorporates important daily skills such as writing and drawing, necessary for the academic achievement of all students. This area includes grasping of pencil, drawing patterns and use of school tools

9. Global motor area

Evaluates the gross-motor skills which are important for an upright posture, walking, running, and climbing. It allows for the observation of physical weakness or disability or defects of movement. This area includes: standing, sitting, parachute reactions, rolling supine-on one side, rolling supineprone, supine - to seated on the floor, seated on the floor — to standing, seated on a chair — to standing, standing — to seated on the floor, standing - to seated on a chair, walking, body spatial orientation in standing, stepping, running, climbing upstairs, descending stairs, jumping, picking up an object from the ground (small ball), playing with a ball and walking on a slope

10. Autonomy in daily life area

Measures early adaptive and self-help behavior typically seen at home, as well as social behavior that develops through early adult-child interactions; therefore, this area analyses the level of autonomy in the praxis of daily life This area includes daily autonomy such as, eating, drinking, coughing or difficulty breathing during meal, type of food's consistence, washing, autonomy in the bathroom and dressing, and other skills such as, playing and socialization skills and advanced autonomy activities

VABS [23] is an assessment scale carried out by interviewing the parents and allow to highlight four domains: communication, daily living, socialization and motor skills. The reliability of the scales was established with reference to skewness, kurtosis and alpha values. Skewness is a measure of the asymmetry, kurtosis is a measure of the combined weight of a distribution's tails relative to the center of the distribution, Cronbach's alpha is the measure of internal consistency. With reference to communication domain the reliability was established as follows: skewness $=0.38$, $\quad$ kurtosis $=0.34$, Cronbach's alpha $=0.89$; the reliability for daily living skills was: skewness $=0.34$, kurtosis $=0.27$, Cronbach's alpha $=0.88$; the reliability for socialization domain was: skewness $=0.69$, kurtosis $=0.76$, Cronbach's alpha $=0.91$; the reliability for motor skills domain was: skewness $=0.87$, kurtosis $=0.67$, Cronbach's alpha $=0.94$. The Cronbach's alpha for the general scale was 0.89 .

RARS [22] is a standardized scale used to evaluate the severity of the disease in patients with RTT. The total score allows to measure the severity of the disease along a continuum ranging from mild symptoms to severe ones. 
Skewness and kurtosis values, calculated for the distribution of the total score, are respectively 0.110 and 0.352 . Distribution is found to be normal. Cronbach's alpha is used to determine the internal consistency for the whole scale and subscales. Total alpha is 0.912 , and the internal consistency of the sub-scales is high (from 0.811 to $0.934)$.

\section{Procedure}

Initially, Airett center professionals contacted the family by phone through a brief interview to collect their availability for GAIRS administration sessions. Then, parents were invited to a session in which they completed the RARS scale [22] that allows to identify the severity of the patients with Rett syndrome, and the Vineland questions [23] to identify behavioral features.

After these sessions, GAIRS Checklist was administered to the patients by the Airett team, composed of a physician, speech therapist and psychologist, during the evaluation sessions at the Rett Center. All professionals had certified, special training on Rett syndrome. Total administration time was around $4 \mathrm{~h}$ (range from 3 to 7) but for the most serious patients it was necessary to divide the administration into multiple sessions (2 or 3 ). Some skill scores that cannot be given directly during the evaluation, such as the item related to the ability to go to the bathroom, was evaluated through video or interview with parents. Every skill was requested ten times, but if the participant gave the first 3 correct answers, the skill was considered acquired; in the same way, if the participant gave the first 3 wrong answers, the skill was considered not acquired.

\section{Results}

Data were analyzed using the Statistical Package for the Social Sciences [29]. We used mean and standard deviation (SD) for the descriptive variables. Normality of the distributions of quantitative variables was verified by applying the Shapiro-Wilk test. Descriptive analysis of both demographic and clinical characteristics of Rett Syndrome patients was performed on the whole cohort. Results were discussed initially with reference to factorial structure of the GAIRS, afterwards, with reference to the internal reliability, and to the correlation for concurrent and divergent validity and finally, with reference to two examples of operational application of GAIRS and suggestions of intervention to two patients.

\section{Factorial structure}

To verify the factorial structure of the GAIRS, exploratory factor analysis (EFA) using principal axis factoring (PAF) was conducted with the Kaiser normalization promax rotation. Finally, we considered Internal Reliability (Cronbach alpha), test-retest reliability, and Correlations for Concurrent and Divergent Validity (Pearson correlations). We considered a two-tailed $\mathrm{p}$ value of 0.05 or less statistically significant.

\section{Descriptive analyses and preliminary analyses}

Tables 3, 4, 5, 6, 7, 8, 9, 10, 11 and 12 show the means and standard deviations for all the items for each subscale of GAIRS. Skewness and kurtosis for all the items were also determined and most items showed normal distribution, while few were positively or negatively skewed.

Inter-subscale correlations were very high (Table 13). All 10 subscales of GAIRS were positively and significantly related to each other and to the total GAIRS score.

Table 3 Means, standard deviations, correct percentages and skewness and kurtosis values of the basic behavior area items

\begin{tabular}{|c|c|c|c|c|c|}
\hline Basic behaviors area & Mean & $\begin{array}{l}\text { Standard } \\
\text { deviation }\end{array}$ & $\%$ & Skewness & Kurtosis \\
\hline Spontaneous eye contact & 3.71 & 1.258 & 74.2 & -.333 & -1.349 \\
\hline Eye contact on request & 3.59 & 1.256 & 71.8 & -.208 & -1.304 \\
\hline Looking at objects & 3.31 & 1.195 & 66.2 & .136 & -1.048 \\
\hline Tracking objects and faces & 3.27 & 1.262 & 65.4 & .027 & -1.089 \\
\hline Functional gestures & 2.24 & 1.129 & 44.8 & .757 & -.093 \\
\hline Cooperation with simple spoken requests & 3.00 & 1.015 & 60.0 & .355 & -.363 \\
\hline Sitting long enough to complete a task & 3.76 & 1.074 & 75.2 & -.203 & -1.281 \\
\hline Object permanence & 2.10 & 1.299 & 42.0 & 1.166 & .297 \\
\hline Be able to wait for their turn before starting an activity & 2.35 & 1.038 & 47.0 & .632 & .257 \\
\hline Be able to communicate basic needs & 2.88 & 1.028 & 57.6 & .416 & -.457 \\
\hline Total score & 3.021 & .9056 & 60.4 & .091 & -.795 \\
\hline
\end{tabular}


Table 4 Means, standard deviations, correct percentages and skewness and kurtosis values of the neuropsychological area items

\begin{tabular}{|c|c|c|c|c|c|}
\hline Neuropsychological area & Mean & Standard deviation & $\%$ & Skewness & Kurtosis \\
\hline Types and intensity of stereotypes & 2.67 & .965 & 53.4 & .361 & -.290 \\
\hline Lateralization & 2.71 & 1.085 & 54.2 & .158 & -.290 \\
\hline Temporal orientation & 1.53 & .979 & 30.6 & .314 & -.290 \\
\hline Spatial orientation & 1.45 & 1.009 & 29.0 & 1.858 & -.290 \\
\hline Memory span & 1.52 & .870 & 30.4 & 2.127 & -.290 \\
\hline Logical sequences & 1.23 & .777 & 24.6 & 1.580 & -.290 \\
\hline Categorization & 1.18 & .730 & 23.6 & 3.270 & -.290 \\
\hline Total score & 1.88 & .7126 & 37.6 & 2.118 & 5.593 \\
\hline
\end{tabular}

Table 5 Means, standard deviations, correct percentages and skewness and kurtosis values of the basic cognitive area items

\begin{tabular}{|c|c|c|c|c|c|}
\hline Basic cognitive area & Mean & Standard deviation & $\%$ & Skewness & Kurtosis \\
\hline Object recognition & 3.43 & 1.174 & 68.6 & .057 & -1.079 \\
\hline Color discrimination & 2.65 & 1.351 & 53.0 & .364 & -.966 \\
\hline Geometric form discrimination & 2.21 & 1.387 & 44.2 & .818 & -.480 \\
\hline Measure concepts & 1.78 & 1.124 & 35.6 & 1.709 & 2.553 \\
\hline Spatial concepts & 1.29 & .844 & 25.8 & 3.204 & 2.450 \\
\hline Human body discriminations & 2.03 & 1.226 & 40.6 & .981 & .185 \\
\hline Time concepts & 1.33 & .943 & 26.6 & 2.973 & 8.404 \\
\hline Cause-effect relationship & 1.19 & .720 & 23.8 & 3.997 & 2.450 \\
\hline Total score & 1.988 & .93 & 39.8 & 1.410 & 1.845 \\
\hline
\end{tabular}

Table 6 Means, standard deviations, correct percentages and skewness and kurtosis values of the advanced cognitive area items

\begin{tabular}{|c|c|c|c|c|c|}
\hline Advanced cognitive area & Mean & $\begin{array}{l}\text { Standard } \\
\text { deviation }\end{array}$ & $\%$ & Skewness & Kurtosis \\
\hline Global words recognition & 1.41 & .922 & 28.2 & 2.478 & 6.227 \\
\hline Syllable's recognition & 1.16 & .721 & 23.2 & 4.703 & 23.010 \\
\hline Recompleting words through syllables & 1.14 & .725 & 22.8 & 4.810 & 23.328 \\
\hline Alphabetic symbols recognition & 1.16 & .801 & 23.2 & 4.524 & 19.700 \\
\hline Recompleting words with alphabetic symbols & 1.15 & .687 & 23.0 & 4.562 & 21.956 \\
\hline Recognition of words representing actions & 1.14 & .752 & 22.8 & 4.700 & 21.512 \\
\hline Using words to communicate & 1.19 & .662 & 23.2 & 3.608 & 14.800 \\
\hline Math pre-requisite concepts & 1.52 & .858 & 30.4 & 1.794 & 3.492 \\
\hline Recognition of numbers & 1.57 & .946 & 31.4 & 1.916 & 3.992 \\
\hline Biunivocal relation between number and quantity & 1.57 & 1.305 & 31.4 & 4.439 & 27.658 \\
\hline Total score & 1.30 & .6938 & 26.0 & 3.620 & 15.089 \\
\hline
\end{tabular}

\section{Exploratory factor analysis}

To verify the factorial structure of GAIRS, PAF was conducted with the Kaiser normalization promax rotation. The use of an EFA approach in a first study testing a new construct such as GAIRS is suitable [30]. Furthermore, the use of PAF is recommended with a violation of the assumption of multivariate normality [31, 32].
The number of factors was determined through Velicer's minimum average partial (MAP) test and parallel analysis [33]. Both the parallel analysis and the original MAP test suggested two factors, and for this reason, a PAF estimation using promax rotation with two-factor solutions was used to explore factor loadings. The twofactor solution was found to explain $60 \%$ of the variance. Almost all the items are loaded into the first factor (that 
Table 7 Means, standard deviations, correct percentages and skewness and kurtosis values of the communication area items

\begin{tabular}{|c|c|c|c|c|c|}
\hline Communication area & Mean & $\begin{array}{l}\text { Standard } \\
\text { deviation }\end{array}$ & $\%$ & Skewness & Kurtosis \\
\hline Expressing a basic need at a physical level & 2.64 & 1.197 & 52.8 & .224 & -.715 \\
\hline Recognizing and expressing a basic need through pictures & 2.33 & 1.250 & 46.0 & .577 & -.562 \\
\hline Understanding the biunivocal relation between the corpora & 2.24 & 1.274 & 44.8 & .725 & -.395 \\
\hline Recognizing and expressing a basic need through word & 1.34 & .952 & 26.8 & 2.755 & 6.876 \\
\hline $\begin{array}{l}\text { Understanding the biunivocal relation of a basic need between a } \\
\text { picture and the word that expresses it }\end{array}$ & 1.24 & .789 & 24.8 & 3.408 & 11.969 \\
\hline Verbal comprehension & 2.83 & 1.068 & 56.6 & -.058 & -.183 \\
\hline Verbal production & 1.42 & .840 & 28.4 & 2.183 & 4.954 \\
\hline Total score & 2.00 & .80343 & 40.1 & 1.123 & 1.550 \\
\hline
\end{tabular}

Table 8 Means, standard deviations, correct percentages and skewness and kurtosis values of the emotional area items

\begin{tabular}{llllcc}
\hline Emotional area & Mean & $\begin{array}{c}\text { Standard } \\
\text { deviation }\end{array}$ & $\%$ & Skewness & Kurtosis \\
\hline Identify emotions & 2.28 & 1.218 & 45.6 & .636 & -.317 \\
Express emotions & 3.04 & 1.038 & 60.8 & -.026 & -.468 \\
Total score & 2.66 & 1.019 & 53.2 & .505 & -.210 \\
\hline
\end{tabular}

explains $40 \%$ of variance) and provide evidence of a general level of abilities which are homogeneous in all subareas. The second factor explains $20 \%$ of the variance and can provide evidence of advanced formal learning abilities (Table 14).

\section{Internal reliability, and correlation for concurrent and divergent validity}

Since we obtained a single general factor explaining $40 \%$ of the variance of GAIRS, we decided to maintain the original sub areas to better describe the general functioning of patients with Rett Syndrome in each of them. For
Table 10 Means, standard deviations, correct percentages and skewness and kurtosis values of the graphomotor area items

\begin{tabular}{lllllc}
\hline Graphomotor area & Mean & $\begin{array}{l}\text { Standard } \\
\text { deviation }\end{array}$ & Skewness & Kurtosis \\
\hline Grasping of pencil & 1.91 & 1.083 & 38.2 & 1.009 & .087 \\
Drawing patterns & 1.72 & 1.016 & 34.4 & 1.475 & 1.516 \\
Use of school tools & 1.41 & .842 & 28.2 & 2.620 & 7.251 \\
Total score & 1.68 & .89508 & 33.6 & 1.560 & 2.341 \\
\hline
\end{tabular}

each subarea, we calculated the alpha levels for internal consistency. Cronbach's alpha values for all the subscales and the total score were high with a range from 0.77 to 0.95 . A test-retest correlation was applied on 58 patients with Rett syndrome 2 months after the first administration and the results were very high $(\mathrm{r}(58)=0.82$, $\mathrm{p}<0.002$ ).

All ten subscales of GAIRS were negatively related with the severity of symptoms of the RARS scale [22] and with neuropsychiatric symptom evaluations, while all the

Table 9 Means, standard deviations, correct percentages and skewness and kurtosis values of the hand motor area items

\begin{tabular}{|c|c|c|c|c|c|}
\hline Hand motor area & Mean & Standard deviation & $\%$ & Skewness & Kurtosis \\
\hline Musculoskeletal alterations & 3.06 & 1.286 & 61.2 & .323 & -.404 \\
\hline Hand-eye coordination during motor tasks & 2.80 & 1.223 & 56.0 & .562 & .326 \\
\hline Lateralization & 2.76 & 1.190 & 55.2 & .442 & -.597 \\
\hline Reaching movement & 2.86 & 1.349 & 57.2 & .386 & -.418 \\
\hline Touching ability & 2.86 & 1.429 & 57.2 & .336 & -.698 \\
\hline Grasping ability & 2.30 & 1.360 & 46.0 & .593 & -.973 \\
\hline Releasing movement & 1.95 & 1.359 & 39.0 & 1.054 & -.285 \\
\hline Repositioning movement & 1.79 & 1.217 & 35.8 & 1.237 & .342 \\
\hline Bimanual coordination & 1.88 & 1.122 & 37.6 & 1.118 & .464 \\
\hline Ability to push and pull an object & 2.00 & 1.363 & 40.0 & 1.196 & .126 \\
\hline Total score & 2.43 & 1.078 & 48.6 & -.752 & 2.426 \\
\hline
\end{tabular}


Table 11 Means, standard deviations, correct percentages and skewness and kurtosis values of the gross motor area items

\begin{tabular}{|c|c|c|c|c|c|}
\hline Gross motor area & Mean & Standard deviation & $\%$ & Skewness & Kurtosis \\
\hline Standing & 3.21 & 1.358 & 64.2 & -.070 & -1.286 \\
\hline Sitting & 3.37 & 1.376 & 67.4 & -.222 & -1.270 \\
\hline Parachute reactions & 2.74 & 1.169 & 54.8 & .563 & -.485 \\
\hline Rolling supine_-on one side & 2.67 & 1.035 & 53.4 & .368 & -.376 \\
\hline Rolling supine-prone & 2.61 & 1.024 & 52.2 & .330 & -.363 \\
\hline Supine- - to seated on the floor & 2.80 & 2.184 & 56.0 & 6.974 & 61.201 \\
\hline Seated on the floor-to standing & 2.55 & .957 & 51.0 & .313 & -.072 \\
\hline Seated on a chair — to standing & 2.59 & .965 & 51.8 & .221 & -.162 \\
\hline Standing - to seated on the floor & 2.52 & .979 & 50.4 & .305 & -.168 \\
\hline Standing — to seated on a chair & 2.56 & .988 & 51.2 & .215 & -.262 \\
\hline Walking & 3.09 & 1.288 & 61.8 & .090 & -1.149 \\
\hline Body spatial orientation in standing & 2.49 & 1.193 & 49.8 & .606 & -.362 \\
\hline Stepping & 2.48 & 1.078 & 49.6 & .572 & -.255 \\
\hline Running & 1.94 & 1.171 & 38.8 & .890 & -.359 \\
\hline Climbing upstairs & 2.36 & .969 & 47.2 & .304 & -.258 \\
\hline Descending stairs & 2.38 & .940 & 47.6 & .356 & -.069 \\
\hline Jumping & 1.23 & .664 & 24.6 & 3.289 & 13.242 \\
\hline $\begin{array}{l}\text { Picking up an object from the ground (small } \\
\text { ball) }\end{array}$ & 1.31 & .873 & 26.2 & 3.070 & 9.551 \\
\hline Playing with a ball & 1.67 & .911 & 33.4 & 1.527 & 2.802 \\
\hline Walking on a slope & 2.34 & 1.085 & 46.8 & 689 & -.006 \\
\hline Total score & 2.46 & .88757 & 49.2 & .505 & .055 \\
\hline
\end{tabular}

Table 12 Means, standard deviations, correct percentages and skewness and kurtosis values of the autonomy in daily life area

\begin{tabular}{|c|c|c|c|c|c|}
\hline Autonomy in daily life area & Mean & Standard deviation & $\%$ & Skewness & Kurtosis \\
\hline Eating & 2.57 & .913 & 51.4 & .886 & .407 \\
\hline Drinking & 2.50 & .870 & 50.6 & 1.079 & 1.156 \\
\hline Coughing or difficulty breathing during meal & 2.83 & 1.016 & 56.6 & .114 & -.681 \\
\hline Type of textures he usually eats & 3.08 & 1.061 & 61.6 & .304 & -.748 \\
\hline Washing & 2.20 & .791 & 44.0 & .624 & .928 \\
\hline Autonomy in the bathroom & 2.07 & .795 & 41.4 & .736 & 1.190 \\
\hline Dressing & 2.11 & 695 & 42.2 & .218 & -.035 \\
\hline Playing area & 2.13 & .812 & 42.6 & .218 & -.566 \\
\hline Socialization area & 2.75 & .903 & 55.0 & -.068 & -.521 \\
\hline Advanced autonomy area & 1.17 & .496 & 23.0 & 3.428 & 3.450 \\
\hline Total score & 2.28 & .70815 & 45.6 & 1.125 & 1.857 \\
\hline
\end{tabular}

subscales of GAIRS were positively correlated with the concurrent measure of the Vineland (Table 15).

\section{Applications of GAIRS and suggestions of intervention} GAIRS scores have a mean of 2.28 and a standard deviation of 0.70 . Based on this, we divided the scores on three levels: patient scores that fall in the 1-1.58 range (where the maximum is $\mathrm{m}$-sd, i.e., 2.28-0.70) show basic competence, patient scores that fall in the 1.59-2.98 range (where the maximum is $\mathrm{m}+\mathrm{sd}$, i.e. $2.28+0.70$ ) show an intermediate level of competence and, finally, patient scores that that fall in the 2.99-5.00 range show a high level of competence.

As an example, below, we present two patients (from our data file) that benefitted from the administration of GAIRS. Emma (name changed for anonymity) has a general score of 1.56, this means that she has a basic level of competence. This index told us nothing about 
Table 13 Inter-subscale correlations among GAIRS' areas

\begin{tabular}{|c|c|c|c|c|c|c|c|c|c|c|c|}
\hline GAIRS Checklist areas & 1 & 2 & 3 & 4 & 5 & 6 & 7 & 8 & 9 & 10 & 11 \\
\hline (1) Basic behaviors area & 1 & & & & & & & & & & \\
\hline (2) Neuropsychological area & $.739 * *$ & 1 & & & & & & & & & \\
\hline (3) Basic cognitive area & $.653^{* *}$ & $.824^{* *}$ & 1 & & & & & & & & \\
\hline (4) Advanced cognitive area & $.435^{* *}$ & $.663^{* *}$ & $.712^{* *}$ & 1 & & & & & & & \\
\hline (5) Communication area & $.699 * *$ & $.787^{* *}$ & $.814^{* *}$ & $.710^{* *}$ & 1 & & & & & & \\
\hline (6) Emotional area & $.626^{* *}$ & $.694^{* *}$ & $.802^{* *}$ & $.643^{* *}$ & $.815^{* *}$ & 1 & & & & & \\
\hline (7) Hand motor area & $.689 * *$ & $.538^{* *}$ & $.430^{* *}$ & $.221^{*}$ & $.524^{* *}$ & $.497^{* *}$ & 1 & & & & \\
\hline (8) Graphomotor area & $.568^{* *}$ & $.635^{* *}$ & $.512^{* *}$ & $.382^{* *}$ & $.577^{* *}$ & $.517^{* *}$ & $.834^{* *}$ & 1 & & & \\
\hline (9) Gross motor area & $.533^{* *}$ & $.580^{* *}$ & $.488^{* *}$ & $.364^{* *}$ & $.572^{* *}$ & $.511^{* *}$ & $.756^{* *}$ & $.730^{* *}$ & 1 & & \\
\hline (10) Autonomy area & $.692^{* *}$ & $.662^{* *}$ & $.561^{* *}$ & $.436^{* *}$ & $.658^{* *}$ & $.591^{* *}$ & $.778^{* *}$ & $.714^{* *}$ & $.859^{* *}$ & 1 & \\
\hline Total score & $.821^{* *}$ & $.844^{* *}$ & $.783^{* *}$ & $.625^{* *}$ & $.838^{* *}$ & $.765^{* *}$ & $.820^{* *}$ & $.805^{* *}$ & $860^{* *}$ & $.892^{* *}$ & 1 \\
\hline
\end{tabular}

${ }^{*} p<0.05 ;{ }^{* *} p<0.01$

intervention. We need to examine all areas of GAIRS: as we can see from Fig. 1, Emma has an intermediate level of gross motor abilities and participation and autonomy. She needs to improve prerequisites. For this reason, it is useful to go more in depth and to disaggregate prerequisite data, as shown in Fig. 2. We can see that while sometimes she looks for people with spontaneous eye contact, she is not able to show eye contact on request, neither look nor trace an object. Then we continue by examining the other areas. Once the hypothesis for each patient was developed, differential reinforcement procedures combined with extinction were designed in order to increase the identified behaviors. For example, the training with Emma has to have the aim of reaching a higher level of visual attention to faces and to objects. Additionally, she may benefit from starting functional communication training and motor training.

Another example of application is the analysis of GAIRS with Anna. Anna (name changed) has a general score of 3.90, this means that she has a high level of competence. Again, we have to examine all areas of GAIRS: as we can see from Fig. 3, Anna has almost a master level in the prerequisites area of abilities and participation and autonomy. The disaggregation of prerequisites shows that she does not need to improve prerequisites (Fig. 4), just the ability to wait. We can continue and disaggregate the other areas and produce the hypothesis for the intervention.

GAIRS scores have a mean of 2.28 and a standard deviation of 0.70 . Based on this, we divided the scores on three levels: patient scores that fall in the 1-1.58 range (where the maximum is m-sd, i.e., 2.28-0.70) show basic competence, patient scores that fall in the 1.59-2.98 range (where the maximum is $\mathrm{m}+\mathrm{sd}$, i.e. $2.28+0.70)$ show an intermediate level of competence and, finally, patient scores that that fall in the 2.99-5.00 range show a high level of competence.

\section{Discussion}

The principal aim of this study was to examine the psychometric characteristics of the GAIRS Checklist. Moreover, the aim was to examine the validity of GAIRS with test-retest correlation, convergent validity with similar functional measurements such as the Vineland scales [23], divergent validity with severity of disease scale such as the RARS [22] scale and neuropsychiatric evaluations.

With reference to the validity of GAIRS, we decided to maintain the original subareas of the Checklist to better describe the general functioning of patients with Rett Syndrome in each of them. For these reasons, this study adds data on the use of the GAIRS Checklist in the global evaluation of patients with RTT. The results of the statistical analysis showed good internal reliability of the scale. Regarding the convergent validity with similar functional measurements such as the Vineland scales, all subscales of GAIRS were positively correlated with the concurrent measure of the Vineland and with neuropsychiatric symptom evaluation. With reference to the severity of disease scale such as the RARS scale and the neuropsychiatric evaluations, all ten sub-scales of GAIRS were negatively related with the severity of symptoms of the RARS scale [22]. All subscales of GAIRS were positively correlated with the concurrent measure of the Vineland and with neuropsychiatric symptom evaluation.

Our experience confirms the previously reported findings and suggests that the GAIRS Checklist can be used to assess behavioral, intellectual, academic, neuropsychological and psychosocial manifestations in patients with Rett Syndrome. The use of this Checklist can be extended to screen for neuropsychiatric involvement in RTT with complex needs. It can be integrated into routine medical 
Table 14 Exploratory factor analysis

\begin{tabular}{|c|c|c|}
\hline GAIRS skills & Components 1 & Components 2 \\
\hline Spontaneous eye contact & .599 & -.128 \\
\hline Eye contact on request & .655 & -.150 \\
\hline Looking at objects & .705 & -.025 \\
\hline Tracking objects and faces & .707 & -.052 \\
\hline Functional gestures & .752 & -.090 \\
\hline Cooperation with simple spoken requests & .631 & .085 \\
\hline Sitting long enough to complete a task & .568 & -.140 \\
\hline Object permanence & .637 & .282 \\
\hline Be able to wait for their turn before starting an activity & .700 & .266 \\
\hline Be able to communicate basic needs & .599 & -.128 \\
\hline Selective attention & .669 & .237 \\
\hline Types and intensity of stereotypes & .452 & .123 \\
\hline Lateralization & .571 & .123 \\
\hline Temporal orientation & .745 & .269 \\
\hline Spatial orientation & .746 & .340 \\
\hline Memory span & .700 & .388 \\
\hline Logical sequences & .683 & .318 \\
\hline Categorization & .706 & .390 \\
\hline Object recognition & .638 & .166 \\
\hline Color discrimination & .641 & .335 \\
\hline Geometric form discrimination & .640 & .406 \\
\hline Measure concepts & .612 & .479 \\
\hline Spatial concepts & .679 & .474 \\
\hline Human body discriminations & .715 & .474 \\
\hline Time concepts & .727 & .456 \\
\hline Cause-effect relationship & .732 & .401 \\
\hline Expressing a basic need at a corporal level & .618 & .177 \\
\hline Recognizing and expressing a basic need through pictures & .639 & .291 \\
\hline Understanding the biunivocal relation between the corpora & .652 & .337 \\
\hline Recognizing and expressing a basic need through word & .674 & .386 \\
\hline Understanding the biunivocal relation of a basic need between a picture and the word & .577 & .485 \\
\hline Verbal comprehension & .712 & .257 \\
\hline Verbal production & .605 & -.105 \\
\hline Identify emotions & .645 & .454 \\
\hline Express emotions & .733 & .059 \\
\hline Musculoskeletal alterations & .512 & -.584 \\
\hline Hand-eye coordination during motor tasks & .594 & -.490 \\
\hline Lateralization & .605 & -.338 \\
\hline Reaching movement & .718 & -.456 \\
\hline Touching ability & .697 & -.434 \\
\hline Grasping ability & .730 & -.380 \\
\hline Releasing movement & .729 & -.262 \\
\hline Repositioning movement & .717 & -.223 \\
\hline Bimanual coordination & .774 & -.177 \\
\hline Ability to push and pull an object & .707 & -.333 \\
\hline Grasping of pencil & .760 & -.290 \\
\hline Drawing patterns & .682 & -.274 \\
\hline Use of school tools & .789 & .037 \\
\hline Standing & .685 & -.317 \\
\hline
\end{tabular}


Table 14 (continued)

\begin{tabular}{|c|c|c|}
\hline GAIRS skills & Components 1 & Components 2 \\
\hline Sitting & .672 & -.410 \\
\hline Parachute reactions & .724 & -.417 \\
\hline Rolling supine_-on one side & .743 & -.401 \\
\hline Rolling supine-prone & .764 & -.336 \\
\hline Supine-to seated on the floor & .799 & -.332 \\
\hline Seated on the floor-to standing & .799 & -.361 \\
\hline Seated on a chair — to standing & .781 & -.321 \\
\hline Standing - to seated on the floor & .785 & -.336 \\
\hline Standing - to seated on a chair & .712 & -.391 \\
\hline Walking & .726 & -.318 \\
\hline Body spatial orientation in standing & .733 & -.315 \\
\hline Stepping & .698 & -.269 \\
\hline Running & .766 & -.270 \\
\hline Climbing upstairs & .768 & -.257 \\
\hline Descending stairs & .545 & .096 \\
\hline Jumping & .705 & -.007 \\
\hline Picking up an object from the ground (small ball) & .766 & -.186 \\
\hline Playing with a ball & .685 & -.475 \\
\hline Walking on a slope & .685 & -.317 \\
\hline Eating & .804 & -.130 \\
\hline Drinking & .816 & -.129 \\
\hline Coughing or difficulty breathing during meal & .629 & -.150 \\
\hline Type of textures he usually eats & .686 & -.268 \\
\hline Washing & .714 & -.145 \\
\hline Dressing & .677 & -.134 \\
\hline Playing area & .600 & -.235 \\
\hline Socialization area & .676 & -.264 \\
\hline Advanced autonomy area & .610 & -.236 \\
\hline Global words recognition & .564 & .627 \\
\hline Syllables recognition & .473 & .615 \\
\hline Recompleting words through syllables & .509 & .599 \\
\hline Alphabetic symbols recognition & .540 & .575 \\
\hline Recompleting words with alphabetic symbols & .557 & .600 \\
\hline Recognition of words representing actions & .537 & .576 \\
\hline Using words to communicate & .574 & .644 \\
\hline Math pre-requisite concepts & .523 & .563 \\
\hline Recognition of numbers & .588 & .601 \\
\hline Biunivocal relation between number and quantity & .564 & .627 \\
\hline
\end{tabular}

The first part of satured items which belong to the first factors has to be in bold, and the second part of the items which belong to the second factor has to be in bold

appointments of individuals and conducted by all the therapists involved in the assessment and intervention with RTT patients. If the aim of the intervention is more related to motor abilities of the girls with Rett syndrome the GAIRS can be integrated with motor scales $[19,20]$.

Furthermore, the checklist can be easily re-administered during follow-up to detect behavioral and psychological changes over time and the efficacy of therapeutic intervention.
These results have interesting implications for future rehabilitation for deeply impaired clinical conditions as in the case of RTT [34-37]. First of all, this study may indicate a way to possibly modify RTT patients' cognitive, motor and communicational structure, and improve their quality of life, as well as the quality of life in the people close to them.

GAIRS indeed is a descriptive assessment that involves completing direct observations in different environments 
Table 15 Correlation among GAIRS score and other assessment instruments

\begin{tabular}{llll}
\hline GAIRS area & $\begin{array}{l}\text { Neuropsychiatric } \\
\text { evaluation }\end{array}$ & RARS score & Vineland score \\
\hline Basic behaviors area & $-.492^{* *}$ & $-.428^{* *}$ & $.651^{* *}$ \\
Neuropsychological & $-.440^{* *}$ & $-.528^{* *}$ & $.628^{* *}$ \\
area & & & \\
Basic cognitive area & $-.377^{* *}$ & $-.510^{* *}$ & $.647^{* *}$ \\
Advanced cognitive & $-.437^{* *}$ & $-.523^{* *}$ & $.374^{*}$ \\
area & & & \\
Communication area & $-.441^{* *}$ & $-.377^{* *}$ & $.680^{* *}$ \\
Emotional area & $-.493^{* *}$ & $-.323^{*}$ & $.586^{* *}$ \\
Hand motor area & $-.437^{* *}$ & $-.289^{*}$ & $.693^{* *}$ \\
Graphomotor area & $-.424^{* *}$ & -.269 & $.677^{* *}$ \\
Gross motor area & $-.416^{* *}$ & $-.327^{*}$ & $.729^{* *}$ \\
Autonomy in daily & $-.434^{* *}$ & $-.476^{* *}$ & $.687^{* *}$ \\
life area & & & \\
Total score & $-.488^{* *}$ & $-.486^{* *}$ & $.726^{* *}$ \\
**p<.01 & & & \\
*p $<.05$ & & &
\end{tabular}

and recording data as behaviors occur in order to determine the maintaining function of a behavior. It provides a structure for assimilation and integration of information leading to mastery of effective clinical reasoning in occupational therapy assessment and intervention. The model adheres to the World Health Organization in the International Classification of Functioning, Disability and Health (ICF) [38], in which both individual and environmental factors that enable or constrain participation in the community are considered in relation to health. The theoretical Model used here is the Applied Behavior Analysis (ABA). ABA is the science in which tactics derived from the principles of behavior are applied systematically to improve socially significant behaviors and experimentation is used to identify the variables responsible for behavior change [39]. ABA methods serve to identify the

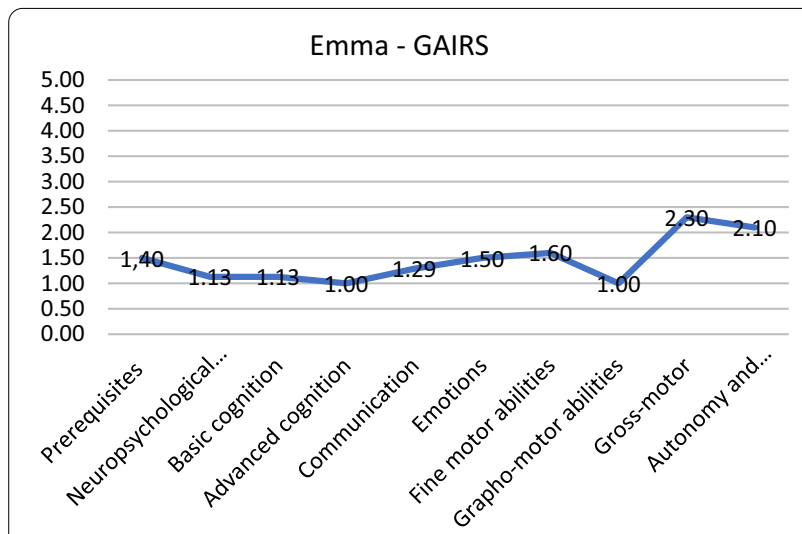

Fig. 1 GAIRS mean scores for each area

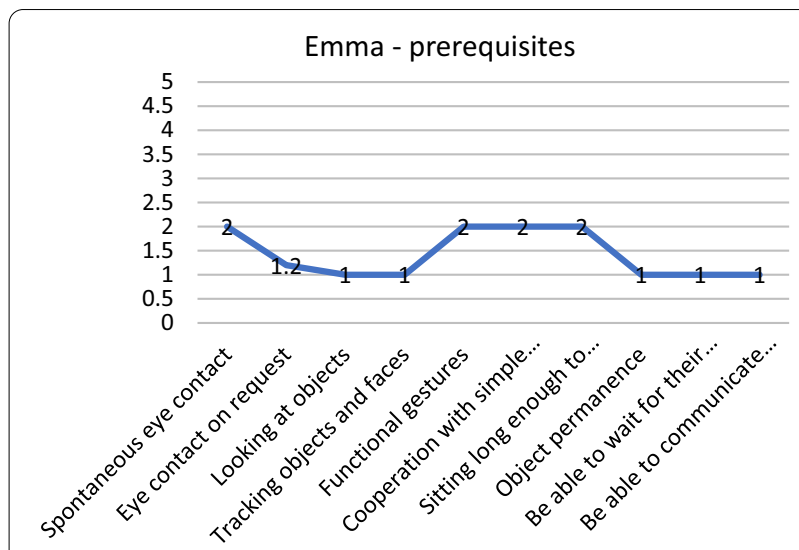

Fig. 2 Prerequisites subarea of GAIRS mean scores

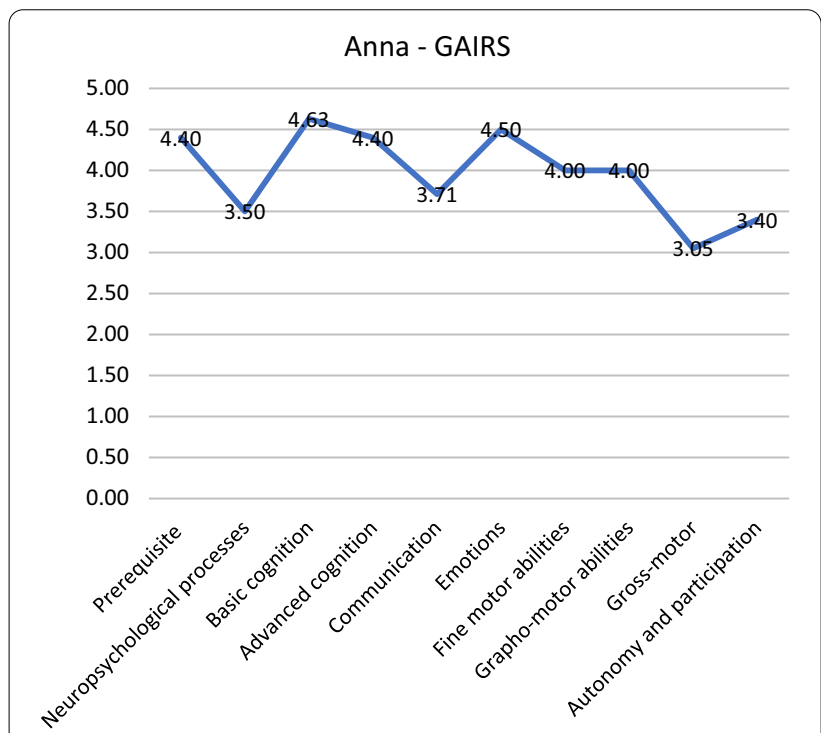

Fig. 3 GAIRS mean scores for each area

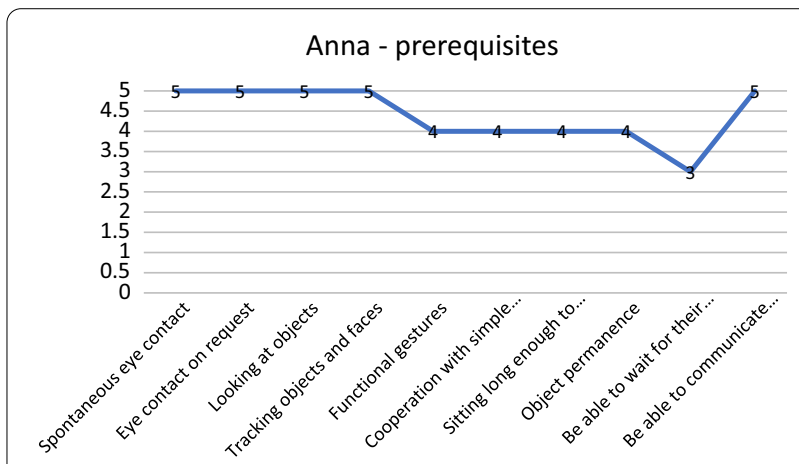

Fig. 4 Prerequisites subarea of GAIRS mean scores 
cause of a behavior and seek ways to improve behavior based on the identified function.

Despite the satisfactory psychometric characteristics, extension studies are warranted, also involving training in order to fully characterize the long-term evolution of GAIRS in Rett syndrome. Lastly, investigating the role intensive and low-frequency trainings on modifying GAIRS areas could provide further evidence about the ability of GAIRS checklist to discriminate between different clinical samples.

\section{Conclusion}

The GAIRS checklist was developed to provide healthcare professionals with a tool to easily screen neuropsychiatric involvement in patients with RTT. The checklist explores the frequency of a wide range of neuropsychiatric manifestations and multiple dimensions of involvement on different levels: behavioral, psychiatric, intellectual, academic, neuropsychological and psychosocial. As these aspects can be impaired in RTT patients, we hypothesized that the checklist could be useful for screening neuropsychiatric needs in this population and for suggesting rehabilitation interventions.

\section{Abbreviations}

RTT: Rett syndrome; GAIRS: Global Assessment and Intervention in Rett Syndrome; VABS: Vineland Adaptive Behavior Scale Interview; RARS: Rett Assessment Rating Scale; RSGMS: Rett Syndrome Gross Motor Scale; RESMES: Rett Syndrome Motor Evaluation Scale; AIRETT: Italian Rett Association.

\section{Acknowledgements}

The authors thank the AIRETT associations of parents for their entusiastic participation.

\section{Authors' contributions}

RAF formulated the idea of the study; RAF, MS and SG drafted and wrote the manuscript. RAF, MS and SG recruited patients for the study. MS and GS conducted the interviews with the families and the patients. RAF performed statistical analysis; RAF, MS and SG were involved in testing the patients. RAF, SG and MS reviewed the manuscript for intellectual content. All the authors revised the draft versions. All authors read and approved the final manuscript.

\section{Funding}

Research funding are from AIRETT (Italian Rett Association).

\section{Availability of data and materials}

The data can be obtained from the corresponding author upon request.

\section{Declarations}

Ethics approval and consent to participate

The ethics committee of the University of Messina approved the study (2019/324) and give consent to the research.

\section{Consent for publication}

Not applicable.

\section{Competing interests}

None of the authors has competing interests to declare.

\section{Author details}

'Department of Clinical and Experimental Medicine, via Bivona, 98121 Messina, Italy. ${ }^{2}$ CARI, (Airett Center Innovation and Research), Vicolo Volto S. Luca, 16, 37100 Verona, Italy. ${ }^{3}$ Catholic University of Milan, Largo Gemelli, 1, 20100 Milan, Italy.

Received: 6 July 2021 Accepted: 20 February 2022

Published online: 05 March 2022

\section{References}

1. Amir R, Van den Veyver I, Wan $M$, et al. Rett syndrome is caused by mutations in X-linked MECP2, encoding methyl-CpG-binding protein 2. Nat Genet. 1999;23:185-8. https://doi.org/10.1038/13810.

2. Fabio RA, Colombo B, Russo S, Cogliati F, Masciadri M, Foglia S, et al. Recent insights into genotype-phenotype relationships in patients with Rett syndrome using a fine grain scale. Res Dev Disabil. 2014;11:2976-86.

3. Fabio RA, Antonietti A, Castelli I, Marchetti A. Attention and communication in Rett syndrome. Res Autism Spectrum Disord. 2009;2:329-35.

4. Hagberg B, Witt-Engerström I. Rett syndrome: a suggested staging system for describing impairment profile with increasing age towards adolescence. Am J Med Genet Suppl. 1986;1:47-59. https://doi.org/10.1002/ajmg.13202 50506.

5. Amir RE, Zoghbi HY. Rett syndrome: methyl-CpG-binding protein 2 mutations and phenotype-genotype correlations. Am J Med Genet. 2000;97(2):147-52. https://doi.org/10.1002/1096-8628(200022)97:2\%3c147: aid-ajmg6\%3e3.0.co;2-o.

6. Cuddapah VA, Robel S, Watkins S, Sontheimer H. A neurocentric perspective on glioma invasion. Nat Rev Neurosci. 2014;15(7):455-65. https://doi.org/10. 1038/nrn3765.

7. Demeter K. Assessing the developmental level in Rett syndrome: an alternative approach? Eur Child Adolesc Psychiatry. 2000;9:227-33.

8. Kaufmann WE, Tierney E, Rohde CA, Suarez-Pedraza MC, Clarke MA, Salorio CF, Bibat G, Bukelis I, Naram D, Lanham DC, Naidu S. Social impairments in Rett syndrome: characteristics and relationship with clinical severity. J Intellect Disabil Res. 2012;56(3):233-47. https://doi.org/10.1111/j.1365-2788. 2011.01404

9. Rodocanachi Roidi ML, Isaias IU, Cozzi F, Grange F, Scotti FM, Gestra VF, et al. A new scale to evaluate motor function in Rett syndrome: validation and psychometric properties. Pediatr Neurol. 2019;100:80-6.

10. Bergström-Isacsson M, Lagerkvist B, Holck U, Gold C. Neurophysiological responses to music and vibroacoustic stimuli in Rett syndrome. Res Dev Disabil. 2014;35(6):1281-91. https://doi.org/10.1016/j.ridd.2014.03.002.

11. Fabio RA, Giannatiempo S, Caprì T. Attention and identification of the same and the similar visual stimuli in Rett Syndrome. Life Span Disabil. 2019;22(1):113-27.

12. Vignoli A, Fabio RA, La Briola F, Giannatiempo S, Antonietti A, Maggiolini S, Canevini MP. Correlations between neurophysiological, behavioral, and cognitive function in Rett syndrome. Epilepsy Behav. 2010;17(4):489-96. https://doi.org/10.1016/j.yebeh.2010.01.024.

13. Didden HCM, Korzilius HPLM, Smeets EEJ, Green VA, Lang R, Lancioni GE, et al. Communication in individuals with Rett syndrome: an assessment of forms and functions. J Dev Phys Disabil. 2010;22(2):105-18.

14. Antonietti A, Marchetti A, Castelli I, Fabio RA, Lucchini B. Do Rett syndrome persons possess theory of mind? Some evidence from not-treated girls. Life Span Disabil. 2013;16:157-68.

15. Townend GS, Bartolotta TE, Urbanowicz A, Wandin E, Curfs L. Development of consensus-based guidelines for managing communication of individuals with Rett syndrome. Augment Altern Commun. 2020;36:71-81. https://doi. org/10.1080/07434618.2020.1785009.

16. Sigafoos J, Woodyatt G, Tucker M, Roberts-Pennell D, Pittendreigh N Assessment of potential communicative acts in three individuals with Rett syndrome. J Dev Phys Disabil. 2000;12:203-16.

17. Battaglia FM, Savoini M. Traduzione e adattamento delle: GMDS-R, Griffiths Mental Development Scale (0-2 anni). Giunti O.S. Firenze; 2007.

18. Holden RH. The Bayley Scales of infant development. In: Buros OK, editor. The seventh mental measurements yearbook, vol. 1. Highland Park: Gryphon Press; 1969. 
19. Downs J, Stahlhut M, Wong K, Syhler B, Bisgaard AM, Jacoby P, Leonard H. Validating the Rett syndrome gross motor scale. PLoS ONE. 2016;1 1(1): e0147555. https://doi.org/10.1371/journal.pone.0147555.

20. Rodocanachi Roidi ML, Isaias IU, Cozzi F, Grange F, Scotti FM, Gestra VF, Gandini A, Ripamonti E. A new scale to evaluate motor function in Rett syndrome: validation and psychometric properties. Pediatr Neurol. 2019;100:80-6. https://doi.org/10.1016/j.pediatrneurol.2019.03.005.

21. Bluma SM. Portage guide to early education. Portage: Cooperative Education Service Agency; 1976. p. 12.

22. Fabio RS, Martinazzoli C, Antonietti A. Costruzione e standardizzazione dello strumento "R.A.R.S." (Rett Assessment Rating Scale). Ciclo evolutivo e disabilità; 2005. p. 8257-81.

23. Sparrow SS. Vineland adaptive behavior scales. In: Kreutzer JS, DeLuca J, Caplan B, editors. Encyclopedia of clinical neuropsychology. New York: Springer; 2011. https://doi.org/10.1007/978-0-387-79948-3_1602.

24. Cervi F, Saletti V, Turner K, Peron A, Bulgheroni S, Taddei M, et al. The TAND checklist: a useful screening tool in children with tuberous sclerosis and neurofibromatosis type 1. Orphanet J Rare Dis. 2020;15(1):1-237.

25. Fabio RA, Antonietti A, Castelli I, Marchetti A. Attention and communication in Rett syndrome. Res Autism Spectrum Disord. 2009;3(2):329-35.

26. Fabio RA, Gangemi A, Capri T, Budden S, Falzone A. Neurophysiological and cognitive effects of Transcranial Direct Current Stimulation in three girls with Rett syndrome with chronic language impairments. Res Dev Disabil. 2018;76:76-87. https://doi.org/10.1016/j.ridd.2018.03.008.

27. Fabio RA, Billeci L, Crifaci G, Troise E, Tortorella G, Pioggia G. Cognitive training modifies frequency EEG bands and neuropsychological measures in Rett syndrome. Res Dev Disabil. 2016;53-54:73-8511.

28. Fabio RA, Caprì T, Nucita A, lannizzotto G, Mohammadhasani N. Eye-gaze digital games improve motivational and attentional abilities in RETT syndrome. J Spec Educ Rehabil. 2018;19(3-4):105-26. https://doi.org/10.19057/ jser.2019.43

29. Statisticale Package for the Social Sciences for Mac, Version 27.0. Armonk: IBM Corp.; 2020.

30. Schmitt TA. Current methodological considerations in exploratory and confirmatory factor analysis. J Psychoeduc Assess. 2011;29:304-21. https:// doi.org/10.1177/0734282911406653.

31. Costello AB, Osborne JW. Best practices in exploratory factor analysis: Four recommendations for getting the most from your analysis. Pract Assess Res Eval. 2005;10(1):7.

32. Fabrigar LR, Petty RE. The role of the affective and cognitive bases of attitudes in susceptibility to affectively and cognitively based persuasion. Pers Soc Psychol Bull. 1999;25:91-109.

33. Velicer WF, Eaton CA, Fava JL. Construct explication through factor or component analysis: a review and evaluation of alternative procedures for determining the number of factors or components. In: Goffin RD, Helmes E, editors. Problems and solutions in human assessment: Honoring Douglas N. Jackson at seventy. Kluwer Academic; 2000. p. 41-71. https://doi.org/10. 1007/978-1-4615-4397-8_3.

34. Fabio RA, Magaudda C, Caprì T, Towey GE, Martino G. Choice behavior in Rett syndrome: the consistency parameter. Life Span Disabil. 2018;21(1):47-62.

35. Friman PC. Cooper, Heron, and Heward's applied behavior analysis (2nd ed.): checkered flag for students and professors, yellow flag for the field. J Appl Behav Anal. 2010;43(1):161-74. https://doi.org/10.1901/jaba.2010.43-161.

36. Antonietti A, Castelli I, Fabio RA, Marchetti A. Teoria della Mente nella sindrome di Rett: effetti di un training. Ciclo Evolutivo e Disabilità. 2001:4:301-29.

37. Castelli I, Antonietti A, Fabio RA, Lucchini B, Marchetti A. Do rett syndrome persons possess theory of mind? Some evidence from not-treated girls. Life Span Disabil. 2013;16(2):157-68.

38. World Health Organization. International classification of functioning, disability and health: ICF. World Health Organization; 2001.

39. Kozloff M, Bates S. A program for families of children with learning and behavior problems. Cogn Behav Ther. 1981;10(1):56-7.

\section{Publisher's Note}

Springer Nature remains neutral with regard to jurisdictional claims in published maps and institutional affiliations.

Ready to submit your research? Choose BMC and benefit from:

- fast, convenient online submission

- thorough peer review by experienced researchers in your field

- rapid publication on acceptance

- support for research data, including large and complex data types

- gold Open Access which fosters wider collaboration and increased citations

- maximum visibility for your research: over 100M website views per year

At BMC, research is always in progress.

Learn more biomedcentral.com/submissions 